\title{
The pedagogical challenges to collaborative technologies ${ }^{1}$
}

\section{Diana Laurillard}

\begin{abstract}
Collaborative technologies offer a range of new ways of supporting learning by enabling learners to share and exchange both ideas and their own digital products. This paper considers how best to exploit these opportunities from the perspective of learners' needs. New technologies invariably excite a creative explosion of new ideas for ways of doing teaching and learning, although the technologies themselves are rarely designed with teaching and learning in mind. To get the best from them for education we need to start with the requirements of education, in terms of both learners' and teachers' needs. The argument put forward in this paper is to use what we know about what it takes to learn, and build this into a pedagogical framework with which to challenge digital technologies to deliver a genuinely enhanced learning experience.
\end{abstract}

\section{Keywords}

Learning theory * Collaborative learning * Pedagogy * Conversational Framework * Constructionism

\section{Introduction}

New kinds of social networking, collaborative, mobile, and user-generated-design technologies are creating exciting opportunities for supporting collaborative learning online. However, digital tools of this kind are rarely developed with the needs of formal learning and teaching in mind. This paper considers how to represent the needs of teachers and learners with respect to collaborative learning, as a way of beginning the learning technology design process from the point of view of user requirements. This is where technology design normally begins, although in this case it is a post hoc process.

Education has not been the source for a user requirements analysis with respect to the new technologies now being explored.

The paper argues that in order to challenge digital technologies to deliver a genuinely enhanced learning experience, it is possible to use the educational theories already developed about what it takes to learn. In the absence of an educational user requirements analysis, there is a need for a pedagogical framework, representing what is known about the nature of the formal learning process, which can challenge the design and use of digital technologies for collaborative learning. The aim is to propose a framework capable of doing that.

Collaborative technologies take different forms, and the boundaries between them are not always clear as technologies become easier to integrate. The paper uses illustrative examples from mobile learning in particular, but is generalised to cover any form of online collaboration in the context of formal learning.

\footnotetext{
${ }^{1}$ International Journal of Computer-Supported Collaborative Learning, 4 (1) 5-20.
} 


\section{From conventional to digital learning designs}

How do we ensure that pedagogy exploits the technology, and not vice versa? A strong theoretical statement about the nature of formal learning, and the requirements this imposes on learning design, enables teachers to make sure they are making the best possible use of the new capabilities on offer. Without this, technology is at risk of being used merely to enhance conventional learning designs, rather than generate designs that are much more effective and innovative. A strong statement would also enable the learning designer to defend the use of digital technology as a unique form of educational technology, able to meet the challenging requirements of the nature of formal learning in ways that conventional methods cannot.

However, a defence of digital against conventional methods requires a theoretical statement that embraces both forms, and it is hard to identify such a comprehensive formulation. A recent theory of the role of Wikis, for example, proposes a model based on a combination of Piaget's cognitive theory (Piaget, 1977) and Luhmann's social systems theory (Luhmann, 1995) to assist our understanding of how they facilitate collaborative knowledge building (Cress \& Kimmerle, 2008). It offers a rich theoretical analysis of how developing a Wiki could help people enhance their individual knowledge through an iterative process of both social and individual cognitive systems. Research to confirm the theory would be valuable for informing the design of Wikis for collaborative learning, but would not necessarily demonstrate the relative advantage of the technology, beyond what a comparative description of its essential characteristics would offer.

Similarly, a proposal for a theory of mobile learning (Sharples, Taylor, \& Vavoula, 2007) describes it as "the process of coming to know through conversations across multiple contexts amongst people and personal interactive technologies" (Ibid, p. 225), locates the theory clearly within a technological context. The idea of conversational learning is valuable for the study of mobile learning, but the theoretical statement privileges interactive technologies. Because it does not embrace both mobile learning and current theories of classroom or workplace learning, it is not a theory that could illuminate the difference between them. In addition, because the analysis of learning as a conversational system is interpreted as if it took the form of a normal conversation, it does not privilege the position of the teacher, as they point out:

We recognize that our theory of mobile learning does not give sufficient importance to what it is that makes a learning activity valuable, to the role of teachers in promoting effective learning, to classrooms as well-organized locations for study, and to educational institutions in extending and validating learners' knowledge. Traditional education needs to be explored in relation to the new world of global knowledge and mobile technology (Ibid, p. 243).

Deleted:

This is an important mission. We must explore traditional methods in their new context, which also means embedding our study of learning through technology within an understanding of the existing classroom, as the authors suggest. However, we can only properly explore "traditional education" in relation to the "new world" from a perspective that is capable of challenging both. A theoretical statement about collaborative learning that embraces all forms of learning and teaching, conventional and digital, mobile and classroom-based, formal and informal, would enable the CSCL community to both challenge and defend the use of technologies.

A recent paper attempted to illustrate the contrast between a conventional teaching design for learning at an art gallery, with a similar design from a research study that made use of 
mobile technologies (Laurillard, 2007). The latter learning design is much richer, primarily because the mobile devices digitally facilitate the link between students, allowing them to collaborate on the collection of data while they are in the site-specific practice environment. The digital facilitation augmented the conventional design by setting up motivating collaborative and competitive transactions between the students, and by requiring contributions to a product at the end of the process. In the conventional version the learning design ends with the teacher's summary - the ideas owned once again by the teacher - whereas in the digitally facilitated version ${ }_{2}$ the students' contributions are displayed in the classroom in the form of captured pictures, annotations, links between pictures, and examples, which together provide a collective answer to the teacher's overall question. In this way, they maintain ownership of the ideas throughout the process. With some effort, it would be possible to achieve the non-digital equivalent of this learning design, but it would be hard to manage, as paper technology does not facilitate this kind of learning design. A clear theoretical statement about collaborative learning should be able to capture this contrast as an account of how technology can enhance the process, which could then inform future design decisions. It should suggest the questions teacherdesigners should ask themselves as they prepare for such a session, and help them to move beyond the conventional.

\section{Ensuring that pedagogy exploits and challenges technology}

Fortunately, we can turn to the traditions of learning theory to help with this. Amid the constant change of technology and its radical effects on the nature of learning and teaching, one thing does not change: what it takes to learn; especially what it takes to learn in the context of formal education.

We know something about pedagogy from over a century of careful analysis of what it takes to learn, from John Dewey onwards (Dewey, 1938). Pedagogical principles focus on different elements of the learning process, and have been characterized successively as:

"instructionism," most prominent in the instructional theories of Gagne, Merrill, and their successors (Gagné, 1970, 1997; Merrill, 1994; Reigeluth, 1983), it influenced the use of the presentational and testing capabilities of the technology, given that the organisation of instruction is the main focus, and technology can be used to test predictable learning through multiple-choice questions, give right/wrong feedback, and select further presentation on that basis;

"constructionism”, deriving from Piaget, but coined by Papert to emphasize the importance of construction of a model or object as an aspect of learning, making use of the programmable, simulation and modelling properties of technology (Papert, 1991);

"socio-cultural learning," deriving from Vygotsky and focusing on the importance of discussion as an aspect of learning, making use of communications technologies (Vygotsky, 1962; Wertsch, 1985);

"collaborative learning," deriving from both Piaget and Vygotsky to combine the social and construction elements of the learning process, making use of integrated technologies capable of supporting both (Dillenbourg,et al., 1996; Scardamalia \& Bereiter, 1994, 2006).

Because each approach focuses on a different aspect of the learning process as being critically important, they generate different conventional teaching methods, and, therefore ${ }_{2}$ different uses of digital technologies. However, none denies the importance of the others.

Deleted:
Deleted:
Deleted:
Deleted:

Deleted: '
Deleted: '
Deleted:
Deleted: '
Deleted: '

Deleted:

Deleted:

Deleted:

Deleted:

Deleted: 
A general account of what it takes to learn, brings together the principal lessons from research on student learning to delineate the minimal essential requirements needed to fully support the formal learning process, whatever form it may take (Laurillard, 2002). In terms of the actors in the teaching and learning process, it is important to represent the teacher, the learner, and the learners' peers. In terms of the transactions between them $\mathrm{m}_{2}$ it was clear that these are quite complex. The simplest way to characterize these complex exchanges was to classify them as operating on two contrasting levels: the discursive, articulating and discussing theory, ideas, concepts, and forms of representation; and the experiential, acting on the world, experimenting and practicing on goal-oriented tasks. Both are essential, no matter what the subject area, and teacher, learner, and other learners need repeated iterative interaction on both levels. And, of course, these two levels of operating have to be connected if learning is to take place. This is where the adaptive and reflective aspects of the learning process are found-adapting actions in the light of understanding, and reflecting on practice to inform theory or concept development. The same applies to teachers - they have to adapt the practice environment to their learners' needs, and then reflect on their performance in order to improve either the task practice, or their own articulation of the theory or concept. With these basic elements of actors and relations as the constituents of the learning process, we can represent each of the pedagogies outlined above.

This enables us to use a general framework for representing learning and teaching, from which to challenge any form of teaching method, whether conventional or technology based. Using a single framework $\mathrm{k}_{2}$ it is possible to represent the four main pedagogic principles outlined above.

Figure 1 shows what the earlier instructional theories tended to prioritize: the presentation of the concept by the teacher, a task goal, which the learner attempts to achieve, and then extrinsic feedback from the teacher in terms of right/wrong comments, hints, new material, or a different task. There is no special focus on interactions with other learners. There is no intrinsic feedback to the learner, that is no information about how close their action was to the goal, or what the effect of their action was. The learner has no opportunity to reflect on the relationship between the goal, their action, and its effect, therefore.

This contrasts with the pedagogy of "constructionism," which does prioritize exactly this aspect of learning. Figure 2 shows how the learner develops their conceptual understanding through repeated attempts to achieve a goal, reflecting on how well their action succeeded in achieving that goal, similar to the Kolb learning cycle (Kolb, 1984). The reflection on the internal relationships between concept, goal, action, feedback, enables them to adjust their current conception. It is the process that happens in our everyday learning: the child trying to fill a bucket from a beaker adjusts their conception of volume; a footballer trying to aim for a goal adjusts their planning for a kick. Something similar happens in formal learning: the child learns about angles in a triangle more easily if they

\section{Insert Figure 1 here}

Figure 1: Instructionism prioritizes the teacher's presentation, and their corrective responses to the learners' performance on the task, either in terms of what they present, or in terms of a new task

try to guide the turtle to draw one, than if they simply watch teacher (Papert, 1980); learners understand composition in painting differently if they try to do it, than if they simply read about it. Again, there is no particular focus on other learners; the important

Comment [MSOffice1] : Begins
with And

\section{Deleted:}

Deleted: i.e. 
focus is the internal relation between concept, goal, and action. That is why intrinsic feedback is so important: It closes the loop.

\section{Insert Figure 2 here}

Figure 2: Constructionism prioritizes the learner's activity in the practice environment, adapted by the teacher to their needs, where it provides intrinsic feedback on their action in relation to the task goal, enabling them to reflect on that internal relation in the light of their action adapted by their current understanding

Sociocultural learning prioritizes the value of discussion with peers as an aspect of learning. It recognizes the value of having to articulate an idea, and to negotiate, in the continual iteration of discussion, the terms of the linguistic representation of an argument or idea. Having to express an idea clarifies for learners what they do not fully understand, especially if their interlocutor is prepared to argue and question. The teacher's role may be minimal, defining the content, in terms of a concept or question for discussion, and the occasion to do it. The reciprocal dialogic process of question-answer, or thesis-antithesis, or point-counterpoint is the productive part of this type of learning, as illustrated in Figure 3 .

\section{Insert Figure 3 here}

Figure 3: Social learning prioritizes the learner's exchange of ideas with a peer or peers, where the teacher's role is to initiate the topic for discussion

Collaborative learning combines constructionism with social learning-sometimes referred to as "social constructivism", (Vygotsky, 1978; Wertsch, 1985). The additional value of this is the opportunity that learners have to share and discuss the actions they take, and the products they make, in the practice environment. This gives focus to their discussion, enables them to learn from and build on the outputs of their peers, and to share their reflections and interpretations of what happened within their practice. The theory could be applied in a variety of contexts to inform the learning design: a teacher might encourage learners to rehearse a speech by practicing it together, rather than simply discussing it, or rehearsing alone; they might set a collaborative task to build a spreadsheet model to facilitate understanding cash flow in a business, so that each learner could see how a partner had tackled the problem, and have the chance to defend their own approach-both parties having the opportunity to learn more. Figure 4 shows how the two pedagogical approaches combine to provide much richer support for the learning process, even without the teacher playing a major role.

This representation clearly defines "collaboration", as distinct from "cooperation," in which the process distributes the required tasks among the learners (Roschelle \& Teasley, 1995). It expresses the essential reciprocity of collaboration, in terms of the iterative dialogue between the learners, and the comparison of the products from their separate attempts to meet a task goal. The results of cooperation can be that learners taking the more directive role in the distribution of tasks learn more than those in other roles (White, 2006) if the "jnstruction-response" pair is always distributed the same way; there is unequal learning, showing the importance of the more reciprocal collaboration format.

\section{Insert Figure 4 here}

Figure 4: Collaborative learning combines the pedagogies of constructionism and social learning to provide richer interactions between learners and their concepts and practice

\section{Deleted: i}

Deleted:

Deleted:

Deleted:

Deleted:

Deleted:

\begin{tabular}{l} 
Deleted: \\
Deleted: \\
Deleted: ' \\
\hline Deleted: '
\end{tabular}

Deleted:

Deleted:

Deleted:

Deleted:

Deleted:

Deleted:

Deleted:

Deleted:

Deleted:

Deleted:

Comment [MSOffice2]: Long sentence 
Putting all these pedagogic approaches together defines the superset of essential requirements for supporting the learning process, a "Conversational Framework," as shown in Figure 5 (Laurillard, 2002). The full framework embraces all the elements prioritized by each of the main pedagogic approaches, and demonstrates the complexity of what it takes to learn: a continual iteration between teachers and learners, and between the levels of theory and practice. It is not symmetrical: The teacher is privileged as defining the conception and designing the practice environment to match. The teacher also learns, from receiving learners' questions and products, as well as reflecting on their performance. But teachers are learning about teaching, rather than learning about the concept or practicing the skill.

The terminology used here is designed to be interpretable across all discipline areas. The word "product", is odd, perhaps, as a way of describing what a learner produces as evidence of their current conceptual understanding, but is generic enough to apply to an essay, lab report, mathematical proof, design, performance, sculpture, that is anything that enables the teacher to make a judgment about the level of understanding the learner has attained. Theories of learning may be interpreted differently in different disciplines, but the fundamental structures should be similar in form. They have been developed from studies carried out at all levels of education, from primary to degree-level, so again, we should expect the generic form to be applicable across all these levels.

Building the Conversational Framework is a way of clarifying that what it takes to learn does not change significantly, no matter how much the technologies of teaching and learning may change. It provides a technology-neutral way of stating the user requirements on any teaching method. Originally developed from an analysis of the educational research on student learning ${ }_{2}$ it suggests that all forms of formal learning require something like this kind of complexity (Laurillard, 2002). It can also be interpreted in terms of "informal learning," where the critical differences from formal learning are that there is no teacher, no defined curriculum topic or concept, and no external assessment. The informal learner selects their own "teacher" who may be a peer, or may not be a person; they define their own "curriculum", as what they are interested in learning about; and they choose whether to submit to "assessment" by others. In that sense, the "Teacher's conception" node is missing. Otherwise, informal learning is just as complex, with the learner using others in their peer group for negotiation of ideas, and their personal context as the source of goals, forms of action ${ }_{2}$ and intrinsic feedback. In fact, if they accept the notion of external assessment of their performance by others, then this kind of acculturation to a social group would have its own equivalents of curriculum and assessment and the role of the teacher.

\section{Insert Figure 5 here}

Deleted: '
Deleted: '

Deleted: $\mathrm{t}$

Deleted: '
Deleted: '
Deleted: i.e.

\begin{tabular}{l} 
Deleted: ' \\
Deleted: ' \\
\hline Deleted: ' \\
\hline Deleted: ' \\
Deleted: ' \\
Deleted: ' \\
Deleted: ' \\
Deleted: ' \\
Deleted: ' \\
Deleted: '
\end{tabular}

Figure 5: The Conversational Framework: instructionism, social learning, constructionism, and collaborative learning combine to provide a simplified representation of what it takes to learn. Numbers show a possible ordering of the successive activities of learner, teacher, and peers.

The value of a framework of this kind is that we can use it to test the true value to learning of any particular teaching method or technology. It is a relatively simple map of the kinds of opportunities a teacher must offer if students are to have a sufficiently complex activity to be able to learn complex ideas and skills. For example, Web_sites and podcasts may 
appear to be exciting new forms of teaching method, but in terms of support to the learning process, they play exactly the same role as conventional books and lectures-they present the teacher's concept. The additional value they offer is logistic rather than pedagogic: They offer more flexible study. The Conversational Framework also demonstrates that a "supervised workshop," with learners working in pairs or groups on a common task to achieve a clearly recognizable product, is a teaching method that fully supports the learning process. It is difficult to find a single technology-based environment that can match it, and thereby, shows that to do so would require the integration of several different kinds of learning technology.

It is important to emphasize that this is not an explanatory theory, as "Conversation Theory" is (Pask, 1976). It is a framework for thinking about the design of learning and teaching, which integrates several theories of learning, and whose representation is based on Pask's analysis of learning as a form of conversation. The Conversational Framework can be used to challenge the pedagogic design of any teaching method, including the technologies of collaboration, whether conventional or digital.

\section{Interpreting the Conversational Framework}

In designing any learning activity, the teacher is essentially planning how to engage the learner in what it takes to learn and demonstrate a particular learning outcome. Any moderately complex outcome will require sustained and effortful cognitive activity of the kind that enables the idea, understanding, or skill, to remain at least until the next time it is rehearsed or needed. The teacher's design must ${ }_{2}$ therefore, ${ }_{2}$ motivate the effortful cognitive activity required of the learner. The inspirational teacher may believe it is enough to tell a fascinating story of what, and how, and why, but many learners need more than that That is why the education system uses formal assessment, which is designed to motivate attention and effort. However, this is external pressure, unrelated to the internal nature of the cognitive effort needed.

In designing any teaching method or learning activity, not just those that are technologybased, we have to ask "why should learners participate?"--and answer by building a sequence of activities that keeps them focused, and thinking at the right level. By uniting the main learning theories in a single representation, the Conversational Framework shows how the iterative cycles required for robust learning work together. Each theory proposes that the learner's conception, and the way they apply it in practice (learner's conception as practice), will develop through iteration with other parts of the Framework, depending on the theory: the teacher, their own practice, debate with their peers, and comparison of their own practice with that of their peers. It ${ }_{2}$ therefore ${ }_{2}$ represents an engine of motivation that keeps the learner engaged as long as the iteration persists. Each part of the Framework has to be interpreted as a cycle that motivates the learner's continued participation. For example, the "Task goal", requires the response that they adapt their action to achieve that goal, using their current conception, which in turn $_{2}$ requires that they make use of the concepts presented by the teacher. The learner's current conception may be rather ill formed at this stage, but feedback on their action requires that they reflect on how well adapted their action was, and creates the possibility that they adapt their current conception in order to improve their revised action. The presence of other learners asking questions or offering their own examples of practice create other cycles of iteration that should motivate the further development of the learner's conception and its application in practice.

Deleted:
Deleted:
Deleted: t
Deleted: '
Deleted: '

Deleted:

Deleted:

Deleted: '
Deleted:
Deleted:

Deleted:

Deleted: 
Figure 5 shows one possible sequence of iteration, which begins with the teacher's presentation. Many others are possible, representing alternative pedagogies. Inquiry-based learning, for example, might begin with the exchange of ideas between learners that would lead them to create questions to the teacher, or to a source of expertise. The "teacher's conception", could be represented as a person, a book, a Web_site, a set of notes-all parts of the Framework are interpretable in terms of a range of media and technologies.

The Conversational Framework can be used to support the decision-making process in learning design by suggesting that we should ask whether it motivates students to engage cognitively, for example to:

- use their current conception to adapt their practice as actions to achieve the goal (5, 6, 7, 8 in Fig 5)?

- revise their actions, using intrinsic feedback to improve their products $(8,9,12,15$ in Fig 5)?

- $\quad$ share their practice products with peers, for comparison and comment $(13,14,15$, 16, 17 in Fig 5)?

- reflect on the experience of the goal-action-feedback cycle by presenting their own conception as a product $(19,20,21,22$ in Fig 5)?

This is a subset of the full set of motivational links implicit in the checklist defining the Conversational Framework (see Annex 1). The opportunity to act on a task goal is not sufficient, for example; the learner also needs intrinsic feedback on their actions. Intrinsic feedback sets up the cognitive conflict between their expectation and the outcome of their actions, and thereby creates the opportunity to reflect on the process and revise them.

The informational content of intrinsic feedback is extremely valuable to the learner. It enables them to know how close they are to a good performance, and what more they need to do. (Laurillard, 2002: 127).

It is the individual equivalent of the motivational drive provided by the cognitive conflict with peers that arises when "the wiki's information differs from their own knowledge" (Cress and Kimmerle, 2008, p. 117), which in Figure 5 would be represented through the action cycle 14, 15, 16 .

\section{Applying the Conversational Framework}

If we now apply this analysis to both conventional and digital learning designs using collaborative mobile technologies, we should be able to see the value of having this more challenging framework.

One particular kind of collaborative learning is characterized as "mobile learning," To illustrate the application of the Framework, we can draw on an example from the literature on mobile learning (Cooket al., 2007; Turcsányi-Szabó, 2007), to compare the way conventional and technology-based methods support learners in building understanding from a field trip in an art gallery (museum, exhibition, science installation, nature trail, geological site, historic site, etc.). A classic learning design for such a trip might include:

(i) a teacher guide to work in pairs in the gallery, guiding them through key paintings and the relations between them; make notes to bring back to class; and

(ii) back in class, the students reporting back and the teacher summarising their comments in terms of the intended understanding.

\begin{tabular}{l|}
\hline Deleted: ' \\
\hline Deleted: ' \\
\hline Deleted: w \\
\hline Deleted: \\
\hline Deleted: \\
Deleted: e.g.
\end{tabular}


To what extent do these two stages motivate learners to engage in understanding? The design is very teacher-focused, enabling them to discuss their ideas as they work through the guide, but not motivating the discussion, except in terms of the report-back, and in a class discussion, it is always possible for an individual to rely on others. Contrast this with what can be done to elaborate the design of the activity (in italics) if students are using mobile phone-computers:

(i) a teacher guide for students to work in pairs in the gallery; the guide has digital codes for each painting; guiding them through key paintings and the relations between them; mobile gives instructions to identify relations between particular paintings, upload their answers and check by downloading the teacher's model answer; asked to set quiz questions to challenge other pairs; and answer challenges from other pairs; record these and their observations on each painting; upload these to a shared Web_site and make notes to bring back to class.

With the opportunity to set more detailed goals, it is possible for the teacher to motivate the iterative exchange of ideas and practice attempts, and build a more elaborated set of notes, and even photos, if the site allows it. The students are encouraged and enabled to engage repeatedly in the goal-action-feedback-reflection-adaptation-revision cycle. Back in class, the learning experience can also be richer:

(ii) back in class, the students reporting back and the teacher summarising their comments in terms of intended understanding, by means of an edited version of the students' outputs collected in the form of a collaborative digital catalogue of the exhibition, and made available on the school Web_site.

Deleted: $w$

The contrast here is that students have an increased sense of ownership of the whole story, their own contributions clearly playing a role in the synthesis of the ideas. The motivational quality of a collaborative output of this kind is much more powerful than a partial contribution to a class discussion. The non-digital world can do something similar with post-it notes and postcards on a classroom wall, of course, but the complexity and quality of the final product would be lacking. The introduction of the digital technology enables the teacher to design at the level of much more precise learning interactions of the kind that Dillenbourg and others (Dillenbourg et al., 1996) argue for: "We have to study and understand the mechanisms of negotiation to a much greater depth than we have so far." (Ibid, p 206). Examples of these more detailed mechanisms might be elaboration, explanation, argumentation ${ }_{2}$ and question asking (Kobbe et al., 2007). But the demand on teachers as learning designers must be simply put. They cannot be expected to undertake the levels of detailed analysis of interaction that researchers engage in (Dillenbourg \& Traum, 2006). However, the implications of these findings can be represented at the level of contrastive descriptions of the affordances of different teaching methods. Digital technologies offer a wider range of affordances than conventional teaching methods, but are only valuable if we have some way of encouraging teachers to take advantage of them, and not simply emulate what they know.

The static representation of the Conversational Framework provides a conceptualization of the process that the teacher must take care to support, but given its complexity, it is useful to supplement this with a checklist version (Annex 1), which emphasizes the importance of motivating the iteration around the Framework. Studies of collaborative learning in a supportive asynchronous environment such as the Knowledge Forum can demonstrate the way motivating iteration, through representations of both theory and practice, improves understanding (Moss \& Beatty, 2006; Scardamalia, 2004; Scardamalia \& Bereiter, 2006). 
The conventional design outlined above does not satisfy the iteration expressed in the numbered actions cycles in Figure 5, and it does not satisfy the checklist points. The checklist is probably the simplest way to express the full requirements, but is neither short nor memorable, so the visual representation in the diagram may help. Figure 6 attempts to represent the dynamic iteration powered by the internal relations in the Framework that motivate the learner's continued effort. The Conversational Framework represents the learner's developing conceptual understanding in terms of successive improvements in both their conception and their mastery of the practical application of theory, as their discursive practice and collaborative environment motivates iteration around the cognitive activities involved.

\section{Insert Figure 6 here}

Figure 6: The Conversational Framework represents the learner's developing conceptual understanding in terms of both theory (achieving some proportion of the teacher's conception) and practical application of theory (in terms of some degree of mastery)

The principal contrast between conventional and digital learning designs should be that the technology facilitates the shift from teacher-focused to learner-focused activities that we see represented in the Conversational Framework: the continual iteration between theory and practice, learner and learner, and learner and teacher, on both levels. Making the best of the technology means exploiting these features, not simply using the digital to emulate the conventional.

\section{Applying the Conversational Framework to forms of collaboration}

This analysis suggests that collaboration is not just social learning, not just discussion of theories, but also an opportunity for intrinsic feedback on the action of "explanation", or "argument", which itself requires reflection. Without a clear representation of the underlying learning theory, CSCL may miss the opportunity to exploit what the technology can do. For example, one framework developed for CSCL categorises the process in terms of participants, activities, roles, resources, and groups (Kobbe et al., 2007), but while this provides a description, it does not explicitly motivate a design; it does not challenge the technology to provide a particular kind of goal, or activity, or form of feedback.

The alternative is to apply a framework such as the Conversational Framework to test whether the design of the collaborative environment is sufficiently rich to support effective learning. As the interaction proceeds, the learner should have opportunities to develop the practical application of the concept, theory, or idea in the context of discussion. They are essentially constructing a shared representation of the concept-and this may be represented only in language. There is a structural difference between the social dimension of learning (the discussion of theory, the exchange of ideas, negotiating meaning) and the practice of discussion and argument in order to develop theory. We can see this by interpreting a particular example of a carefully designed collaborative learning session, an "Argue-Graph", script (Jermann \& Dillenbourg, 2003), in terms of the extent to which it covers the Conversational Framework requirements. The design of the session is summarised as:

Students first individually argue for or against items on a questionnaire. Their opinion is plotted onto a two-dimensional graph. Students with highly conflicting opinions (point distance in the graph) are grouped together in pairs and receive another copy of the questionnaire to fill out. Students discuss what arguments to

\section{Deleted:}

\section{Deleted:}

\begin{tabular}{l|}
\hline Deleted: ' \\
\hline Deleted: ' \\
\hline Deleted: ' \\
Deleted: '
\end{tabular}


write for each item. The teacher collects the questionnaires and helps each small group $_{2}$ in turn ${ }_{2}$ to elaborate on and revise their arguments. The teacher then groups all arguments by item. Finally, each student is assigned one item for which to write a synthesis of all arguments. (Kobbe et al., 2007, p. 215)

The summary outlines the logistics of the process, which the Conversational Framework cannot represent, but if we look at the design from the learner's perspective, and discern the nature of their unfolding experience, we can map the pedagogical intention of the successive stages onto most of the Conversational Framework, as shown in the likely chronological order in Figure 7.

\section{Insert Figure 7 here}

Figure 7: An "Argue-Graph" script mapped onto the Conversational Framework, showing the succession of learning activities planned into the design, where learner $\mathrm{L}_{2}$ has the same relationship with $\mathrm{L}_{1}$, and all groups of students have the same internal relation as that between $\mathrm{L}_{1}$ and $\mathrm{L}_{2}$. Their respective answers instantiate their ideas as practice.

The design of the Argue-Graph script requires more than an exchange of ideas: It affords the construction of a shared representation of the concept. There is no external practice environment providing intrinsic feedback, such as a lab, or an audience, or a simulation, but there is a form of intrinsic feedback provided by how the learner's constructed answer to a question compares with that of their peer. The requirement to produce a refined set of arguments and a shared understanding serves the purpose of motivating adaptation of their constructed answer in the light of each learner's reflection on peer feedback on their action. The component activities posited for this script-“"a) justifying opinions and constructing arguments; b) comparing, evaluating, and elaborating; c) negotiating and constructing arguments; d) explaining and justifying opinions; e) summarizing and making connections" (Kobbe et al., 2007)-are all mapped in Figure 7. The chronology of the Argue-Graph script as a pedagogic design is working in a similar way to the toolmediated construction activity reported by Hmelo-Silver (2003), and the sequence of collaborative activities recorded by Luckin (Luckin et al., 2001; Luckin, 2003).

A conventional tutorial may operate simply at the level of exchanging ideas, as exemplified in the "social script", (Weinberger, Ertl, et al., 2005). This would map directly onto the social learning representation in Figure 3, where learners are not asked to construct a shared argument, but simply offer comments on each other's analysis:

Three case studies are analyzed and reviewed by groups of three students in parallel. Each student writes a case analysis, then critiques the other two written case analyses and finally revises his/her own case analysis based on the critiques received by the other students. Both roles of case analyst and constructive critic are additionally supported with text prompts that learners are supposed to act out, such as "These aspects are not clear to me yet"; "We have not reached consensus concerning these aspects"; and "My proposal for an adjustment of the analysis is" for the critic's role. (Kobbe et al., 2007, p. 215)

Of course, there is value in this, as for a conventional tutorial, but the learner has far less motivation or opportunity here, than in the Argue-Graph script, to reflect on the quality of their ideas, and reconstruct their argument. It is an empirical question as to whether there is evidence for this in the evaluation of these scripts, but they have not been evaluated in this way, because there is no underlying theory to offer such a hypothesis. The advantage

\section{Deleted:}

Deleted: i

Deleted:

Deleted:

Deleted:

Deleted:

Deleted: Hmelo-Silver,

Deleted:

Deleted:

Deleted: 
of the Conversational Framework is that it provides a proposal for a design pattern that is testable, and improvable, not a simple description.

A conventional "social learning", tutorial is valuable, therefore, but should achieve a better pedagogical design by creating a "practice environment", for the learners to share and revise their constructed arguments. Online collaborative environments such as the Knowledge Forum, provide exactly these features for sharing, obtaining feedback on, and revising an argument (Scardamalia \& Bereiter, 2006). It is important to distinguish this kind of orchestrated construction of an argument from the exchange of ideas that is a natural part of many academic encounters, because it addresses the separation between articulation of the theory and critical comparison and evaluation of the arguments. It is a separation that allows the social sciences and humanities to work within the constructionist methodology, where intrinsic feedback is often not provided by an external system, but from a contrasting constructed argument.

As a framework for pedagogic design, therefore, the Conversational Framework goes beyond providing a description of the components of a collaborative process, to an account of how the different components of the pedagogic design interrelate to motivate the learner to conceptualise, adapt, act, reflect, revise, negotiate, share, and produce, that is, to rehearse and repeat what it takes to learn.

Deleted: '
Deleted: '
Deleted: '
Deleted: '

Deleted: i.e.

Deleted:

Deleted:

Deleted:

Cook, J., Bradley, C., Lance, J., Smith, C., \& Haynes, R. (2007). Generating learning contexts with mobile devices. In N. Pachler (Ed.), Mobile learning: Towards a research agenda. Vol 1, 25-38. London: WLE Centre for Excellence, Institute of Education.

Cress, U., \& Kimmerle, J. (2008). A systemic and cognitive view on collaborative knowledge building with wikis. International Journal of Computer-Supported Collaborative Learning, 3(2), 105-122.

Dewey, J. (1938). Experience and education. New York: Kappa Delta Pi.

Deleted:

Formatted: Font: Italic

Deleted: $E$ 
Dillenbourg, P., Baker, M., Blaye, A., \& O'Malley, C. (1996). The evolution of research on collaborative learning. In E. Spada \& P. Reiman (Eds.), Learning in humans and machine: Towards an interdisciplinary learning science, (pp. 189-211). Oxford, UK: Elsevier.

Dillenbourg, P., \& Traum, D. (2006). Sharing solutions: Persistence and grounding in multimodal ccollaborative problem solving. Journal of the Learning Sciences, 15(1), 121-151.

Gagné, R. M. (1970/1997). The Conditions of Learning (3rd ed.). New York: Holt, Rinehart and Winston.

Hmelo-Silver, C. E. (2003). Analyzing collaborative knowledge construction: multiple methods for integrated understanding. Computers \& Education, 41, 397-420.

Jermann, P., \& Dillenbourg, P. (2003). Elaborating new arguments through a CSCL script. In J. Andriessen, M. Baker, \& D. Suthers (Eds.), Arguing to learn: Confronting cognitions in computer-supported collaborative learning environments, (pp. 205226). Dordrecht, Netherlands: Kluwer.

Kobbe, L., Weinberger, A., Dillenbourg, P., Harrer, A., Hamalainen, R., Hakkinen, P., Fischer, F. (2007). Specifying computer-supported collaboration scripts. International Journal of Computer-Supported Collaborative Learning, 2(2), 211224.

Kolb, D. A. (1984). Experiential learning: experience as the source of learning and development. Englewood Cliffs, NJ; Prentice-Hall.

Laurillard, D. (2002). Rethinking university teaching: A çonversational framework for the effective usse of learning technologies (2nd ed.). London: RoutledgeFalmer.

Laurillard, D. (2007). Pedagogical forms for mobile learning: Framing research questions. In N. Pachler (Ed.), Mobile learning: Towards a research agenda. Vol. 1, 153175. London: WLE Centre for Excellence, Institute of Education.

Luckin, R., Plowman, L., Laurillard, D., Stratfold, M., Taylor, J., \& Corben, S. (2001). Narrative evolution: learning from students' talk about species variation. International Journal of Artificial Intelligence in Education, 12, 100-123.

Luckin, R. (2003). Between the lines: documenting the multiple dimensions of computersupported collaborations. Computers \& Education, 41(4), 379-396.

Luhmann, N. (1995). Social systems. Palo Alto, CA: Stanford University Press.

Merrill, M. D. (1994). Instructional design theory. Englewood Cliffs, NJ: Educational Technology Publication.

Moss, J., \& Beatty, R. (2006). Knowledge building in mathematics: Supporting collaborative learning in pattern problems. International Journal of ComputerSupported Collaborative Learning, 1, 441-465.

Papert, S. (1980). Mindstorms: Children, computers, and powerful iddeas. Brighton, Sussex: The Harvester Press.

Papert, S. (1991). Situating constructionism. In I. Harel \& S. Papert (Eds.), Constructionism: research reports and essays, 1985-1990,(pp.1-11). Norwood, N.J.: Ablex Publishing Corporation,

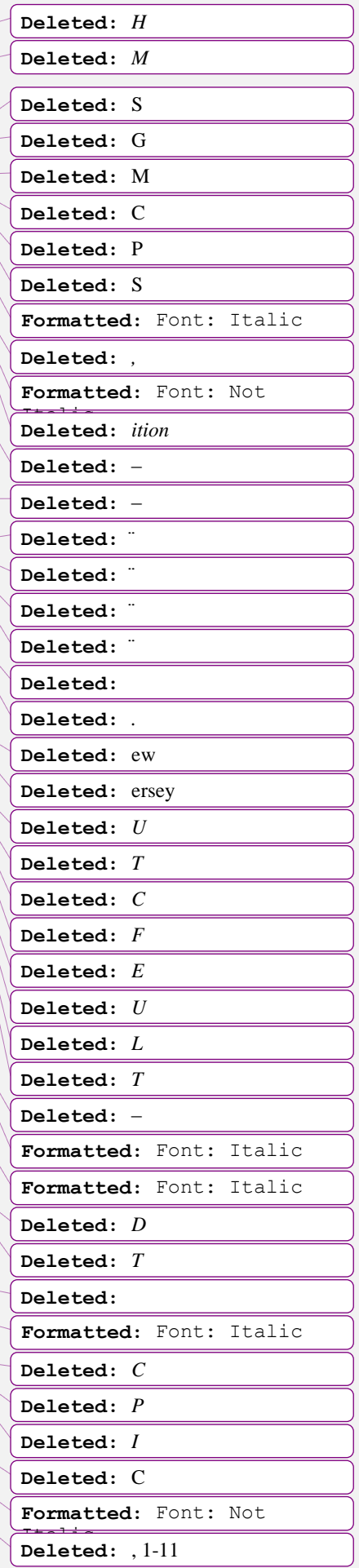


Pask, G. (1976). Conversation theory: Applications in education and epistemology. Amsterdam: Elsevier.

Piaget, J. (1977). Problems of equilibration. In M. H. Appel \& L. S. Goldberg (Eds.), Topics in cognitive development, Vol. 1, 3-14. New York: Plenum.

Reigeluth, C. M. (1983). Instructional-design theories and models: An overview of their current status. Mahwah, NJ: Lawrence Erlbaum Associates.

Roschelle, J., \& Teasley, S. D. (1995). The construction of shared knowledge in collaborative problem solving. In C. O'Malley (Ed.), Computer-supported collaborative learning, (pp. 69-97). Berlin, Germany: Springer.

Scardamalia, M. (2004). CSILE/Knowledge forum®. In A. Kovalchick \& K. Dawson (Eds.), Education and technology: An encyclopedia, (pp. 183-192. Santa Barbara, CA.: ABC-CLIO, Inc.

Scardamalia, M., \& Bereiter, C. (1994). Computer support for knowlege-building communities. Journal of the Learning Sciences, 3(3), 265-283.

Scardamalia, M., \& Bereiter, C. (2006). Knowledge building: Theory, pedagogy and technology. In K. Sawyer (Ed.), Cambridge handbook of the learning sciences, (pp. 97-118). Cambridge, UK: Cambridge University Press.

Sharples, M., Taylor, J., \& Vavoula, G. (2007). A theory of learning for the mobile age. In R. Andrews \& C. Haythornthwaite (Eds.), The Sage handbook of e-learning research, (pp. 221-247). London: Sage Publications Ltd.

Turcsányi-Szabó, M. (2007). Collaborative trails: The role of trails in structuring and regulating collaboration. In J. Schoonenboom, M. Levene, J. Heller, K. Keenoy ${ }_{2} \&$ M. Turcsnyi-Szabo (Eds.), Trails in education: Technologies that support navigational learning, (pp. 59-84). Amsterdam: Sense Publishers.

Vygotsky, L. (1962). Thought and language. Cambridge MA: MIT Press.

Vygotsky, L. S. (1978). Mind in society: The development of higher psychological processes. Cambridge, MA.: Harvard University Press.

Weinberger, A., Ertl, B., Fischer, F., \& Mandl, H. (2005). Epistemic and social scripts in computer-supported collaborative learning. Instructional Science, 33(1), 1-30.

Wertsch, J. V. (1985). Cultural, communication, and çognition: Vygotskian perspectives. Cambridge: Cambridge University Press.

White, T. (2006). Code talk: Student discourse and participation with networked handhelds. International Journal of Computer-Supported Collaborative Learning (ijCSCL), 1(3), 359-382.

Deleted: $T$
Deleted: $E$
Deleted: $E$

Deleted: $D$

Deleted: $T$

Deleted: $M$

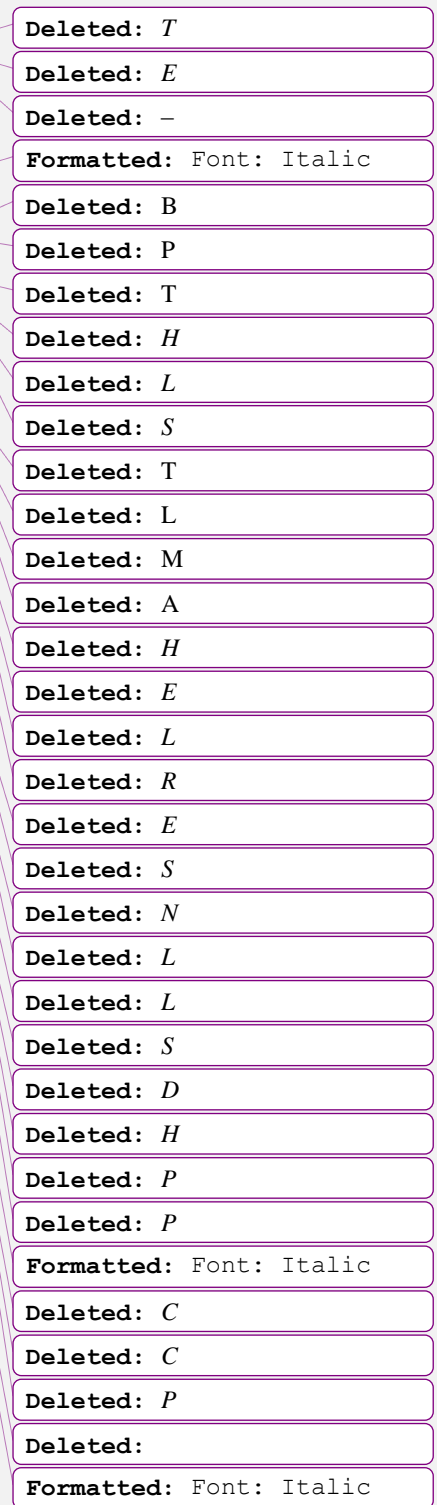




\section{Annex 1: A Summary of the Conversational Framework}

The Conversational Framework poses the following checklist of questions to the learning activities planned for a learning session. Each question checks an action cycle in the Framework. Numbers in brackets refer to Figure 5.

Do they motivate students to:

1. access explanations and presentations of the theory, ideas or concepts $(1,6)$ ?

2. ask questions about their understanding of the theory, etc, by providing the opportunity for answers from the teacher $(2,3)$, or their peers $(10,11)$ ?

3. offer their own ideas and conceptual understanding, by providing comment on them from the teacher, or their peers?

4. use their theoretical understanding to achieve a clear task goal by adapting their actions in the light of their understanding $(5,6,7)$, or in response to comments $(10$, $11)$ or feedback (8)?

5. repeat practice, by providing feedback on actions that enables them to improve performance $(5,6,7,8)$ ?

6. repeat practice, by enabling them to share their trial actions with peers, for comparison and comment $(13,14,15,16,17)$ ?

7. reflect on the experience of the goal-action-feedback cycle, by offering repeated practice at achieving the task goal $(5,6,7,8,9,12,19,20,21)$ ?

8. discuss and debate their ideas with other learners $(10,11)$ ?

9. reflect on their experience, by having to articulate or produce their ideas, reports, designs, performances, etc. for presentation to their peers $(13,14,15,16)$ ?

10. reflect on their experience, by having to articulate or produce their ideas, reports, designs, performances, etc. for presentation to their teachers $(21,22)$ ? 